\title{
Reaction-Induced Cluster Ripening and Initial Size-Dependent Reaction Rates for CO Oxidation on $\mathrm{Pt}_{n} / \mathrm{TiO}_{2}(110)-(1 \times 1)$
}

\author{
Simon Bonanni, Kamel Aït-Mansour, Wolfgang Harbich, and Harald Brune* \\ Institute of Condensed Matter Physics, Ecole Polytechnique Fédérale de Lausanne (EPFL), CH-1015 Lausanne, Switzerland
}

ABSTRACT: We determined the $\mathrm{CO}$ oxidation rates for sizeselected $\mathrm{Pt}_{n}(n \in\{3,7,10\})$ clusters deposited onto $\mathrm{TiO}_{2}(110)$. In addition, we investigated the cluster morphologies and their mean sizes before and after the reaction. While the clusters are fairly stable upon annealing in ultrahigh vacuum up to $600 \mathrm{~K}$, increasing the temperature while adsorbing either one of the two reactants leads to ripening already from $430 \mathrm{~K}$ on. This coarsening is even more pronounced when both reactants are dosed simultaneously, i.e., running the $\mathrm{CO}$ oxidation reaction. Since the ripening depends on the size initially deposited, there is nevertheless a size effect; the catalytic activity decreases monotonically with increasing initial cluster size.

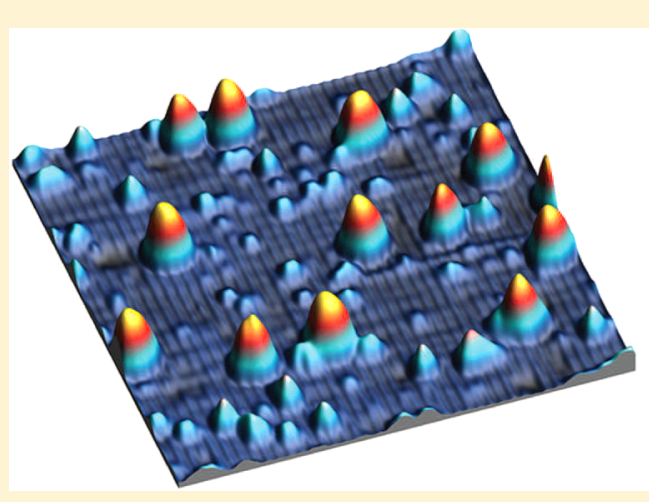

stability under the reaction conditions sets a clear limitation to the minimum cluster size that can be reasonably employed.

Here we present a systematic study of the initial sizedependent reactivity and of the thermal as well as chemical stability of very small Pt clusters on rutile $\mathrm{TiO}_{2}(110)-(1 \times 1)$ in a weak reduction state.

\section{EXPERIMENTAL SECTION}

The experiments were performed in an ultrahigh vacuum (UHV, $p_{\text {tot }} \leq$ $1 \times 10^{-10}$ mbar) chamber combining size-selected cluster deposition, low-temperature scanning tunneling microscopy (STM), and catalytic activity measurements with a highly sensitive detector. ${ }^{25,26}$

Clean $\mathrm{TiO}_{2}(110)$ surfaces were prepared in UHV by repeated cycles of $\mathrm{Ar}^{+}$sputtering $(1 \mathrm{kV}, 13 \mu \mathrm{Ah}, 300 \mathrm{~K})$ and annealing at $950 \mathrm{~K}$ for 15 min. This procedure is known to preferentially remove oxygen, ${ }^{27}$ leading to $\mathrm{TiO}_{2-\delta}$ crystals with a slight oxygen deficiency. ${ }^{28}$ This nonstoichiometry results in surface and bulk oxygen vacancies $\left(\mathrm{O}_{\text {vac }}\right)$, as well as in interstitial titanium $\mathrm{Ti}_{3}{ }^{+28-30}$ The crystal reduction state $\delta$ strongly influences the reactivity of adsorbed metal clusters. ${ }^{13}$ This is reflected in the surface $O_{\text {vac }}$ concentration that is determined by STM. ${ }^{13,31,32}$ Since the reduction state of the crystal changes during the course of several sample preparations, and in order to compare the strength of its effect with the initial size effect we are after, the cluster deposition experiments were carried out in the sequence $\mathrm{Pt}_{10} \rightarrow \mathrm{Pt}_{7} \rightarrow$ $\mathrm{Pt}_{3} \rightarrow \mathrm{Pt}_{3} \rightarrow \mathrm{Pt}_{7}$; i.e., we repeated $\mathrm{Pt}_{3}$ in the fourth sample and then came back to $\mathrm{Pt}_{7}$ in the fifth in order to compare with the same size studied on a less reduced substrate in sample 2. The $\mathrm{O}_{\text {vac }}$ concentration is given in monolayers $(\mathrm{ML}) ; 1 \mathrm{ML}$ is one vacancy per $\mathrm{TiO}_{2}(110)-(1 \times 1)$ unit cell and corresponds to a density of $5.2 \times$ $10^{14} \mathrm{~cm}^{-2}$. The first $\mathrm{TiO}_{2-\delta}(110)$ sample of this sequence had $0.04 \mathrm{ML}$ $\mathrm{O}_{\mathrm{vac}}$ and the last $0.06 \mathrm{ML}$.

The cluster source is based on sputtering of a metal target by 20 $\mathrm{keV} \mathrm{Kr}^{+}{ }^{33}$ Cluster cations are extracted, energy filtered, and mass selected by a quadrupole. The ionized particles are directed to the

Received: March 21, 2014

Published: May 28, 2014 


\section{as deposited}
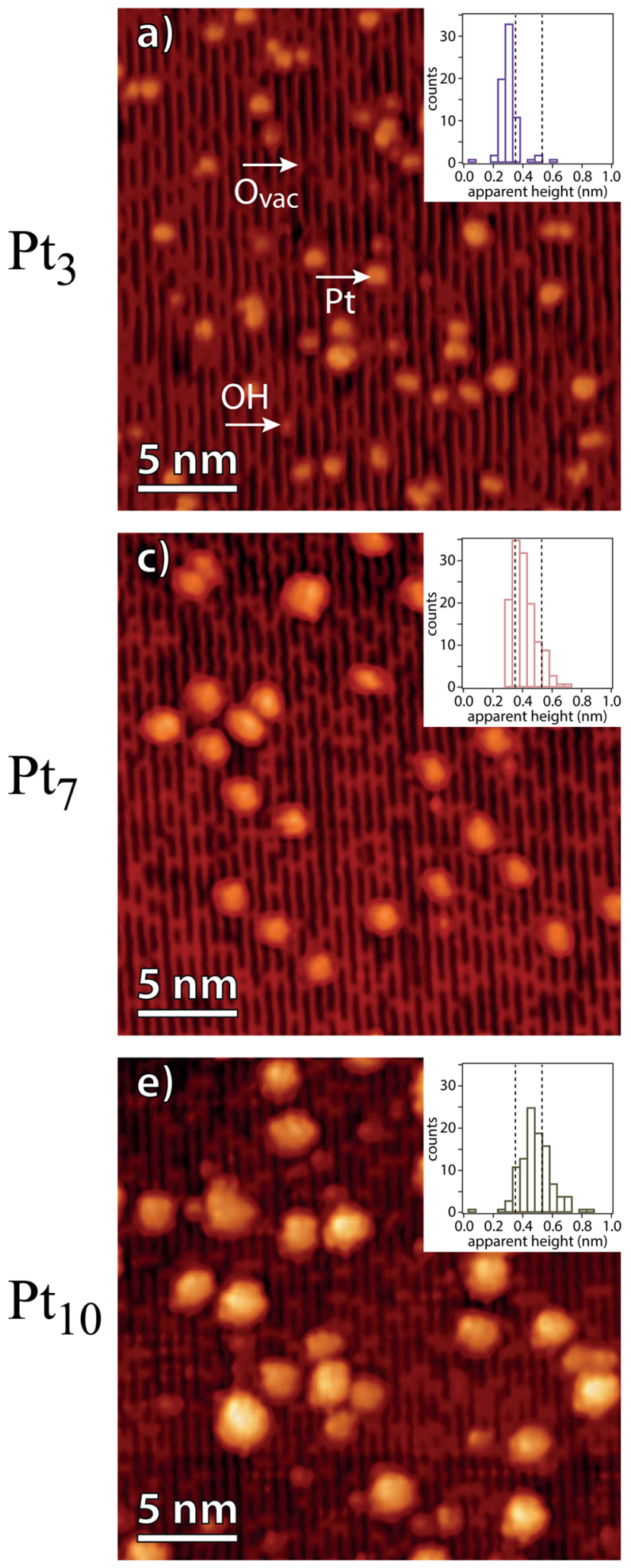

after reaction
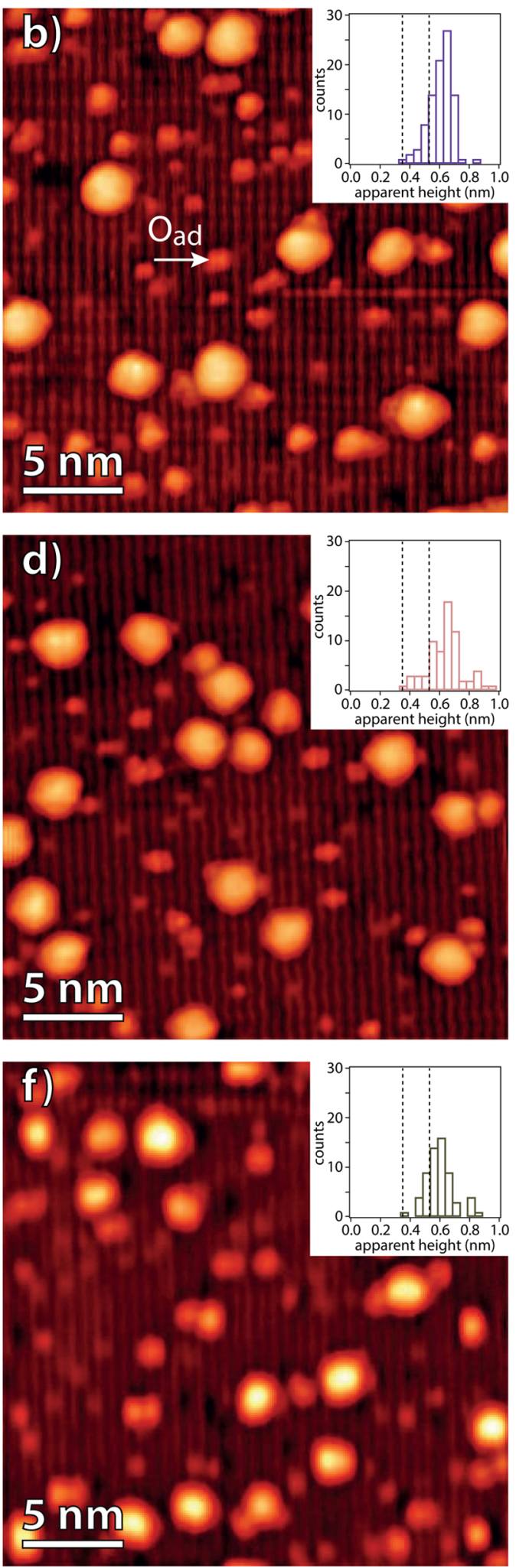

Figure 1. STM images of size-selected $\mathrm{Pt}_{3}(\mathrm{a}, \mathrm{b}), \mathrm{Pt}_{7}(\mathrm{c}, \mathrm{d})$, and $\mathrm{Pt}_{10}(\mathrm{e}, \mathrm{f})$ on $\mathrm{TiO}_{2}(110)-(1 \times 1)$ as deposited (left) and after catalytic reaction (right) with exposure to $\mathrm{CO}$ and $\mathrm{O}_{2}$ up to a surface temperature of $600 \mathrm{~K}$. The insets show apparent height distributions.

surface whose potential defines the kinetic energy of deposition held at $7 \mathrm{eV} /$ atom for all sizes investigated. This energy is a compromise between the optimum kinetic cluster energy for the quadrupole and soft landing conditions. ${ }^{34}$ We adjusted the cluster density to obtain an overall Pt coverage of $0.02 \mathrm{ML}$, where $1 \mathrm{ML}$ here is defined as an atomic density of $\mathrm{Pt}(111)$ of $1.5 \times 10^{15}$ atoms $/ \mathrm{cm}^{2}$. The Pt coverage is obtained from the cluster current density times the deposition time and the cluster size. The clusters were deposited at room temperature, 
and typical cluster currents were $550 \mathrm{pA}$ for $\mathrm{Pt}_{3}, 230 \mathrm{pA}$ for $\mathrm{Pt}_{7}$, and $200 \mathrm{pA}$ for $\mathrm{Pt}_{10}$ on a sample surface of $0.25 \mathrm{~cm}^{2}$.

The catalytic activity of the samples was measured by recording the $\mathrm{CO}_{2}$ signal while dosing alternating pulses of the reactants $\mathrm{CO}$ and $\mathrm{O}_{2}$ into a confined volume right in front of the sample surface. ${ }^{26}$ In order to increase the selectivity with respect to molecules from the residual gas, we dosed ${ }^{18} \mathrm{O}_{2}$ and ${ }^{13} \mathrm{C}^{16} \mathrm{O}$ and detected ${ }^{13} \mathrm{C}^{18} \mathrm{O}^{16} \mathrm{O}$. Each of the pulses corresponded to an exposure of the sample to $0.08 \mathrm{~L}$ (langmuir) $\mathrm{CO}$ (where $1 \mathrm{~L}=1.33 \times 10^{-6} \mathrm{mbar} \cdot \mathrm{s}$ ) and $0.7 \mathrm{~L} \mathrm{O}_{2}$. Each pulse sequence lasted $10 \mathrm{~s}$, and the sample temperature was increased from 300 to $600 \mathrm{~K}$ at a rate of $1 \mathrm{~K} / \mathrm{s}$, thus over 30 pulses. This enables to determine the $\mathrm{CO}_{2}$ reaction rate as a function of sample temperature for each of the deposited cluster sizes. ${ }^{13}$

STM images were taken directly after cluster deposition and after exposure to the reactants. Comparison of the respective cluster densities and apparent heights allowed us to detect cluster ripening and morphology transformations induced by the adsorption and reaction enthalpy, respectively. The apparent cluster height histograms were obtained by analyzing $\sim 200$ clusters per sample. The STM images were recorded in constant current mode at $V_{\mathrm{t}}=1.5 \mathrm{~V}$ and $I_{\mathrm{t}}=$ $100 \mathrm{pA}$ at a temperature of $80 \mathrm{~K}$.

\section{RESULTS}

STM images after deposition of $\mathrm{Pt}_{3}, \mathrm{Pt}_{7}$, and $\mathrm{Pt}_{10}$ are shown in the left-hand column of Figure 1. In agreement with the literature, ${ }^{13,28}$ the $\mathrm{TiO}_{2}(110)$ terraces display parallel bright and dark stripes corresponding to titanium atom rows and bridging oxygen atom rows of the un-reconstructed surface. The atomic steps (not shown) have an apparent height of $3.2 \AA$, and the shallow protrusions on the dark lines are $\mathrm{O}_{\text {vac }}{ }^{13}$ In addition, the terraces exhibit very few $\mathrm{OH}$ groups as a consequence of water dissociation from the residual gas. ${ }^{13,35}$ The larger features correspond to Pt clusters. Their apparent size (height as well as width) clearly increases from $\mathrm{Pt}_{3}$ to $\mathrm{Pt}_{10}$. The clusters are not all imaged in the same way. This is mostly due to different conformations of the same size. Cluster fragmentation and coalescence by cluster diffusion would give rise to a polydisperse size distribution that would also be imaged in a non-uniform way. However, cluster diffusion is absent at $300 \mathrm{~K}$, as concluded from the fact that the clusters are equally distributed over the surface; in particular, there is no accumulation at substrate steps. Fragmentation is judged to be negligible on the basis of the cluster densities agreeing for all three sizes very well with the ones expected from the respective cluster currents and deposition times.

From the histograms shown as insets, one can infer that the great majority of $\mathrm{Pt}_{3}$ has an apparent height reminiscent of one atomic Pt layer $(0.35 \mathrm{~nm}){ }^{36}$ Most of the $\mathrm{Pt}_{7}$ clusters are also one atomic layer high; however, there is a clear tail toward double-layer height that is absent for $\mathrm{Pt}_{3}$. $\mathrm{Pt}_{10}$ clusters have a symmetric histogram centered at double-layer height, with equal weights on single- and triple-layer apparent heights. These apparent height distributions are in excellent agreement with the ones reported by Isomura et al. ${ }^{36}$ These authors deposited atoms in the soft landing regime with a kinetic energy of $1.2 \mathrm{eV} /$ atom. $^{34}$ Hence, this agreement further supports our conclusion of cluster fragmentation and diffusion being negligible.

The right-hand column of Figure 1 shows the surface after catalytic activity measurements, i.e., after exposure of the sample to alternating pulses of the two reactants, $\mathrm{O}_{2}$ and $\mathrm{CO}$, while the temperature was increased from 300 to $600 \mathrm{~K}$. From the cluster densities we infer significant coarsening. The clusters now have a mean size of 12,14 , and 16 atoms. Hence, $\mathrm{Pt}_{3}$ ripens more than $\mathrm{Pt}_{10}$, in line with the expectation of larger clusters being more stable against both Smoluchowski and Ostwald ripening. Note also the change in the apparent height distributions. In all cases, the clusters now are mostly double layers, with the most abundant apparent height being slightly above the double layer. The apparent cluster volume increase is related to tip convolution effects, which are larger for the higher clusters.

Before discussing cluster coarsening in more detail, we focus on the reaction rate as a function of the initial cluster size and temperature. Figure 2 shows that the $\mathrm{CO}_{2}$ production rate per

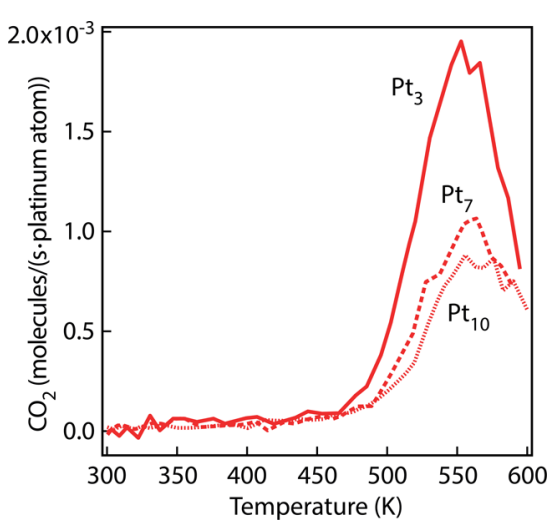

Figure 2. $\mathrm{CO}_{2}$ production rates per Pt density as a function of deposited cluster size and temperature.

Pt atom is highest for an initial size of 3 atoms. Albeit the mean size on which the reaction takes place increases during the temperature ramp and gas exposure, there is a clear initial size dependence, since this coarsening depends on the initial size. The $\mathrm{CO}_{2}$ production rate is essentially given by the $\mathrm{CO}$ adsorption and desorption kinetics. We find that $\mathrm{CO}$ blocks the oxygen dissociation and thereby the reaction below $470 \mathrm{~K}$, as in a real catalyst, and the temperature profiles of the reaction rates are compatible with thermal desorption spectra of $\mathrm{CO}$ desorbing from Pt nanoparticles. ${ }^{37}$ In addition to the reaction rates, also the temperatures at which these rates reach their respective maximums show an initial size dependence. The temperature is largest for $\mathrm{Pt}_{10}$, which is expected since $\mathrm{CO}$ is slightly more strongly bound to larger Pt clusters.

Figure 3 shows the maximum reaction rates as a function of $n^{-2 / 3}$, where $n$ is the initial size. One sees a linear behavior with an intercept at 0 . If we assume, in a crude model, the cluster volume to be proportional to $n$, the surface to $n^{2 / 3}$, and the perimeter to $n^{1 / 3}$, we find the relative length-to-volume ratio to depend on $n^{-2 / 3}$. The perimeter-to-volume ratio has to go to zero for large clusters. Both the linearity and the interception are reflected in the measurements. Note that no other scaling like the surface-to-volume ratio which goes with $n^{-1 / 3}$ is represented by the experimental data. We take this as an indication that $\mathrm{O}_{2}$ dissociates at the low-coordinated perimeter sites. This has been found, for example, in calculations for $\mathrm{Au}$ clusters but not for Pt clusters on titania. ${ }^{38}$ One also recognizes the spread of the data as a function of the sample reduction state. The sequence of points was $\mathrm{Pt}_{10}, \mathrm{Pt}_{7}, \mathrm{Pt}_{3}$, all shown in black, followed by $\mathrm{Pt}_{3}$ and $\mathrm{Pt}_{7}$, both shown in red. The first sample had 0.04 $\mathrm{ML} \mathrm{O}_{\text {vac }}$ and the last 0.06 ML. In agreement with our previous work, ${ }^{13}$ the reaction rates go down with increasing surface $\mathrm{O}_{\mathrm{vac}}$ density; however, the initial size effect is independent of the substrate reduction state. 


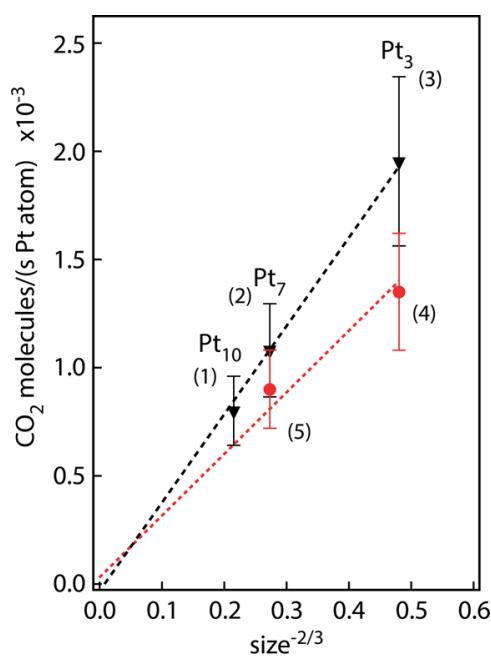

Figure 3. $\mathrm{CO}_{2}$ production rates per Pt atom as a function of $n^{-2 / 3}$ (where $n$ is the initial size), showing in addition to the initial size effect the evolution with substrate reduction state that increases from 0.04 $M L \mathrm{O}_{\text {vac }}$ for the first sample $\left((1) \mathrm{Pt}_{10}\right.$, black point) to $0.06 \mathrm{ML}$ in the last $\left((5) \mathrm{Pt}_{7}\right.$, red point).

In order to shed more light on the conditions that influence the cluster stability, and to understand at which size catalyst particles can operate in a stable way, we studied the morphology and size of deposited Pt heptamers as a function of temperature and gas exposure. $\mathrm{Pt}_{7}$ clusters were deposited with a nominal platinum coverage of $0.025 \mathrm{ML}$ and then annealed to the temperatures indicated on the right-hand side in Figure 4, under the conditions given in the columns of this figure, namely, under vacuum and while dosing with $\mathrm{O}_{2}, \mathrm{CO}$, and a 1:1 mixture of both reactants. The reactant pressure was $1 \times 10^{-6} \mathrm{mbar}$, and the annealing time $600 \mathrm{~s}$. Thereby, the exposure was more than 20 times higher than in the experiments discussed above. After the exposure/annealing, the samples were cooled to $80 \mathrm{~K}$ for STM measurements.
The clusters are remarkably stable against annealing in UHV. The apparent height histogram does not change until $430 \mathrm{~K}$, and it changes very little at $520 \mathrm{~K}$; only at $600 \mathrm{~K}$ annealing temperature is there a significant peak at $0.6 \mathrm{~nm}$, reminiscent of double-layer height. ${ }^{36}$ The mean cluster size of this experiment, shown in Figure 5 as a black curve, does not change until 430

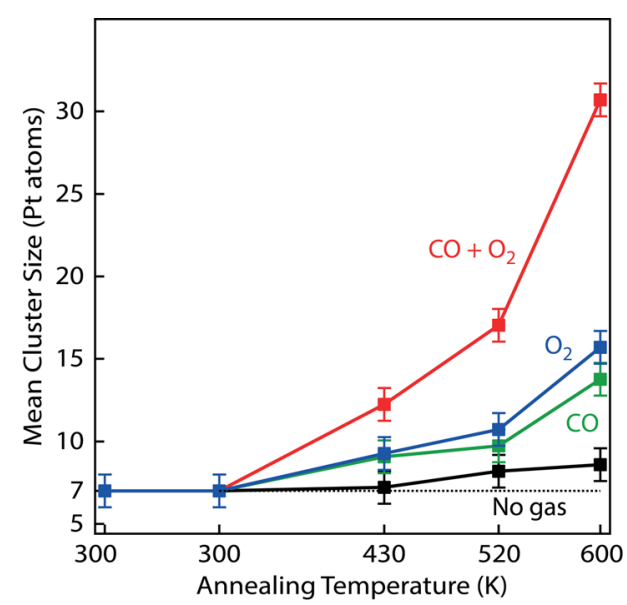

Figure 5. Mean size of deposited $\mathrm{Pt}_{7}$ cluster after annealing in a vacuum (black) and exposure to $\mathrm{O}_{2}$ (blue), $\mathrm{CO}$ (green), and both reactants (red). Conditions as in Figure 4.

$\mathrm{K}$; it then increases slightly to $8.2 \pm 1.0 \mathrm{Pt}$ atoms per cluster at $520 \mathrm{~K}$, and stays within the error bar at this value after annealing to $600 \mathrm{~K}$. Exposure of the clusters to oxygen induces a significant broadening of the apparent height distribution, with bilayer clusters being most abundant and equal parts of mono- and trilayer clusters. The mean size increases already at $430 \mathrm{~K}$ to $10.7 \pm 1.0$ atoms per cluster. The same mean size is found for exposure to $\mathrm{CO}$ at this temperature. However, comparing the histograms, we see a clear monolayer-to-bilayer transition above $520 \mathrm{~K}$, which is not the case for oxygen. Further increase of the temperature during exposure to either

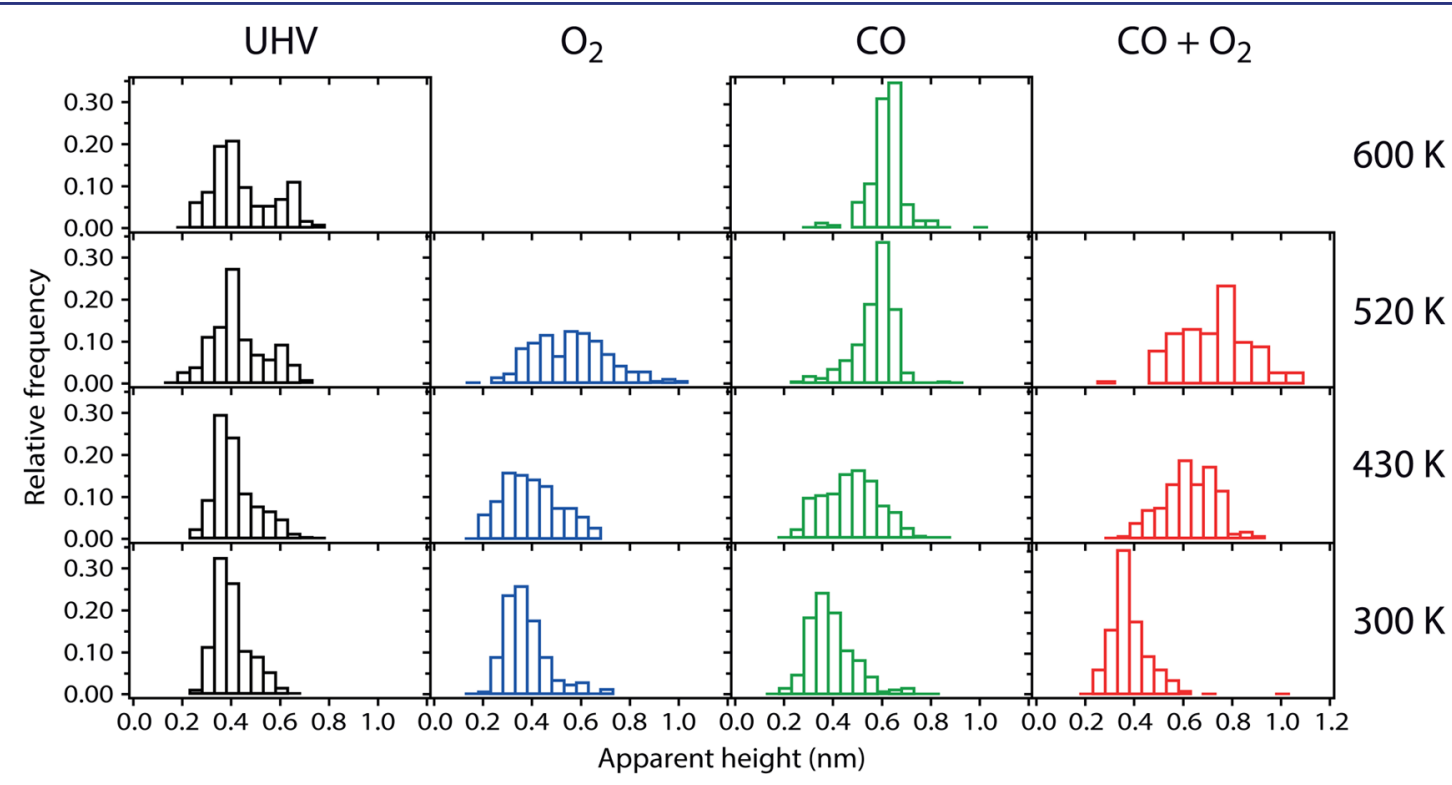

Figure 4. Apparent height distributions of deposited $\mathrm{Pt}_{7}$ clusters after annealing in UHV (black) and exposure to $\mathrm{O}_{2}$ (blue), $\mathrm{CO}$ (green), and both reactants (red). Conditions: Pt coverage, $0.025 \mathrm{ML}$; annealing time, $600 \mathrm{~s}$; heating rate, $2 \mathrm{~K} / \mathrm{s}$; STM measurements at $80 \mathrm{~K}$; partial pressure during exposure, $1 \times 10^{-6} \mathrm{mbar}$. 
one of the reactants leads to further ripening to a mean size of $\sim 15$ atoms per cluster, while the shape of the apparent height histograms does not change markedly. STM images show in addition that, upon $\mathrm{O}_{2}$ exposure, the Pt clusters are surrounded by a $\mathrm{TiO}_{x}$ ring; ${ }^{13,39}$ this ring is absent for $\mathrm{CO}$ exposure. $\mathrm{CO}$ induced morphology changes were reported for larger $\mathrm{Pt}$ nanoparticles and attributed to $\mathrm{CO}$-assisted Ostwald ripening, i.e., to the disintegration of the supported metal particles upon the formation of surface carbonyls that transport $\mathrm{Pt}$ preferentially from the smaller to the larger clusters. ${ }^{19,40}$ No transition states resulting from the disintegration of Pt clusters have been observed in our experiment. The coarsening of $\mathrm{Pt}$ clusters is even more pronounced under reaction conditions, i.e., when both reactants are dosed simultaneously. The histograms show a clear shift to triple-layer clusters already at $520 \mathrm{~K}$, and the red curve of the mean cluster size is far above the other ones, culminating in a mean size of $30 \pm 1 \mathrm{Pt}$ atoms per cluster upon running the $\mathrm{CO}$ oxidation at $600 \mathrm{~K}$. A very similar observation was made for vapor-grown $\mathrm{Au}$ clusters on titania $^{23}$ and larger gold clusters on $\mathrm{TiC}^{24}$ From the significantly greater coarsening with respect to the separate exposure to the reactants, we conclude that the excess energy of the reaction of about $2.9 \mathrm{eV}^{41}$ is involved in the morphology change. Hot electrons have been reported during $\mathrm{CO}$ oxidation on $\mathrm{Pt}$ nanoparticles on $\mathrm{TiO}_{2}{ }^{42,43}$ The observed reactioninduced enhancement of coarsening can therefore proceed via an electronic excitation of the cluster substrate system.

Our findings shed new light on catalysis experiments over size-selected surface-adsorbed metal clusters. Evidently, the extent to which cluster ripening occurs depends on the clustersubstrate interaction. However, the present results encourage us to check the cluster morphology and mean size before and after the reaction of interest.

One of the first experiments on size-selected metal clusters was performed for $\mathrm{Pt}_{n}$ on $\mathrm{MgO}(100)$ thin films grown on $\mathrm{Mo}(100){ }^{6}$ In contrast to the present study, the authors adsorbed both reactants at low temperature and used temperature-programmed reaction. They found a more or less constant $\mathrm{CO}_{2}$ production rate up to $\mathrm{Pt}_{14}$, and a sudden increase by a factor of 3 on going to $\mathrm{Pt}_{15}$. This was attributed to the size-dependent ionization potential of $\mathrm{Pt}$ clusters matching at a given size the antibonding $\pi_{\mathrm{g}}^{*}$ orbital of oxygen. These early experiments did not investigate the cluster morphology by means of STM.

The $\mathrm{CO}$ oxidation rates on $\mathrm{Pt}_{n} / \mathrm{TiO}_{2}(110)$ were investigated under high reactant pressures and at elevated temperatures of $572-625 \mathrm{~K}^{12}$ These results are different from ours, as the authors reported an increase of the catalytic activity up to $\mathrm{Pt}_{7-8}$, followed by a decrease until $\mathrm{Pt}_{10}$, where it reached a stationary value. The reactivity increase was attributed to the transition from mono- to bilayer clusters, as observed by means of STM before the reaction. The absence of coarsening and of morphology transitions was concluded from X-ray photoelectron spectroscopy of the $\mathrm{Pt} 4 \mathrm{f}_{7 / 2}$ states, which showed them to have constant energy before and after the reaction. However, STM investigation of the mean cluster size and apparent height distribution after the reaction would have been a more stringent test. The difference with respect to our results can therefore be attributed to the different degree of coarsening due to the different reaction conditions, in addition to possible differences in the substrate reduction state.

\section{CONCLUSION}

We report size-dependent $\mathrm{CO}$ oxidation rates for size-selected Pt clusters on titania, correlating catalytic reactivity to cluster morphology before and after catalytic reaction measurements. We find a linear increase of this rate with the surface-to-volume ratio of atoms. In contrast to similar studies on very small sizeselected clusters, ${ }^{6,36}$ this indicates no or only a weak dependence of a size-specific electronic structure. Apart from the fact that reactivity is strongly dependent on the substrate reduction state, ${ }^{13}$ which has been taken care of by choosing substrates of comparable reduction states, the stability of the metal clusters upon the reaction itself is an important parameter. Our measurements show a reaction-enhanced sintering which results in a final cluster size distribution different from the deposited one. This sets a minimum size limit in the study of size-selected cluster catalysis. In the case of $\mathrm{Pt}_{n} / \mathrm{TiO}_{2}$, we observe sintering during the oxidation of $\mathrm{CO}$ for all sizes up to the decamer, despite the $\mathrm{Pt}$ clusters being thermally stable in the absence of exposure to the reactants, a commonly used argument for stability. Therefore, control or at least knowledge of the cluster morphology in catalytic activity measurements is of fundamental importance.

\section{AUTHOR INFORMATION}

\section{Corresponding Author}

harald.brune@epfl.ch

Notes

The authors declare no competing financial interest.

\section{ACKNOWLEDGMENTS}

This work has been supported by the Swiss National Science Foundation.

\section{REFERENCES}

(1) Landman, U. Proc. Natl. Acad. Sci. U.S.A. 2005, 102, 6671.

(2) Gao, F.; Goodman, D. W. Annu. Rev. Phys. Chem. 2012, 63, 265.

(3) Fayet, P.; Granzer, F.; Hegenbart, G.; Moisar, E.; Pischel, B.; Wöste, L. Phys. Rev. Lett. 1985, 55, 3002.

(4) Abbet, S.; Riedo, E.; Brune, H.; Heiz, U.; Ferrari, A. M.; Giordano, L.; Pacchioni, G. J. Am. Chem. Soc. 2001, 123, 6172.

(5) Abbet, S.; Sanchez, A.; Heiz, U.; Schneider, W. D.; Ferrari, A. M.; Pacchioni, G.; Rösch, N. J. Am. Chem. Soc. 2000, 122, 3453.

(6) Heiz, U.; Abbet, S.; Sanchez, A.; Schneider, W. D. J. Am. Chem. Soc. 1999, 121, 3214

(7) Heiz, U.; Vanolli, F.; Sanchez, A.; Schneider, W. D. J. Am. Chem. Soc. 1998, 120, 9668

(8) Wörz, A. S.; Judai, K.; Abbet, S.; Heiz, U. J. Am. Chem. Soc. 2003, 125,7964

(9) Yoon, B.; Hakkinen, H.; Landman, U.; Wörz, A. S.; Antonietti, J. M.; Abbet, S.; Judai, K.; Heiz, U. Science 2005, 307, 403.

(10) Kaden, W. E.; Wu, T.; Kunkel, W. A.; Anderson, S. L. Science 2009, 326, 826 .

(11) Lee, S.; Fan, C.; Wu, T.; Anderson, S. L. J. Am. Chem. Soc. 2004, 126,5682

(12) Watanabe, Y.; Wu, X.; Hirata, H.; Isomura, N. Catal. Sci. Technol. 2011, 1, 1490

(13) Bonanni, S.; Ait-Mansour, K.; Harbich, W.; Brune, H. J. Am. Chem. Soc. 2012, 134, 3445.

(14) Sitja, G.; Le Moal, S.; Marsault, M.; Hamm, G.; Leroy, F.; Henry, C. R. Nano Lett. 2013, 13, 1977-1982.

(15) Fukamori, Y.; Konig, M.; Yoon, B.; Wang, B.; Esch, F.; Heiz, U.; Landman, U. ChemCatChem 2013, 5, 3330-3341.

(16) Behafarid, F.; Cuenya, B. R. Top. Catal. 2013, 56, 1542.

(17) Campbell, C. T.; Parker, S. C.; Starr, D. E. Science 2002, 298, 811. 
(18) Parker, S. C.; Campbell, C. T. Phys. Rev. B 2007, 75, 035430.

(19) Berko, A.; Szoko, J.; Solymosi, F. Surf. Sci. 2004, 566-568, 337.

(20) Gao, F.; Wang, Y.; Cai, Y.; Goodman, D. W. J. Phys. Chem. C 2009, 113, 174.

(21) Simonsen, S. B.; Chorkendorf, I.; Dahl, S.; Skoglundh, M.; Sehested, J.; Helveg, S. J. Am. Chem. Soc. 2010, 132, 7968.

(22) Simonsen, S. B.; Chorkendorf, I.; Dahl, S.; Skoglundh, M.; Meinander, K.; Jensen, T. N.; Lauritsen, J. V.; Helveg, S. J. Phys. Chem. C 2012, 116, 5646.

(23) Yang, F.; Chen, M. S.; Goodman, D. W. J. Phys. Chem. C 2009, 113, 254.

(24) Ono, L. K.; Sudfeld, D.; Cuenya, B. R. Surf. Sci. 2006, 600, 5041-5050.

(25) Jödicke, H.; Schaub, R.; Bhowmick, A.; Monot, R.; Buttet, J.; Harbich, W. Rev. Sci. Instrum. 2000, 71, 2818.

(26) Bonanni, S.; Aït-Mansour, K.; Hugentobler, M.; Brune, H.; Harbich, W. Eur. Phys. J. D 2011, 63, 241.

(27) Henderson, M. A. Surf. Sci. 1995, 343, L1156.

(28) Diebold, U. Surf. Sci. Rep. 2003, 48, 53.

(29) Wendt, S.; Sprunger, P. T.; Lira, E.; Madsen, G. K. H.; Li, Z.; Hansen, J. .; Matthiesen, J.; Blekinge-Rasmussen, A.; Lægsgaard, E.; Hammer, B.; Besenbacher, F. Science 2008, 320, 1755.

(30) Yim, C. M.; Pang, C. L.; Thornton, G. Phys. Rev. Lett. 2010, 104, 036806.

(31) Lira, E.; Hansen, J. Ø.; Huo, P.; Bechstein, R.; Galliker, P.; Lægsgaard, E.; Hammer, B.; Wendt, S.; Besenbacher, F. Surf. Sci. 2010, $604,1945$.

(32) Lira, E.; Wendt, S.; Huo, P.; Hansen, J. Ø.; Streber, R.; Porsgaard, S.; Wei, Y.; Bechstein, R.; Lægsgaard, E.; Besenbacher, F. J. Am. Chem. Soc. 2011, 133, 6529.

(33) Vandoni, G.; Félix, C.; Monot, R.; Buttet, J.; Harbich, W. Chem. Phys. Lett. 1994, 229, 51.

(34) Bromann, K.; Félix, C.; Brune, H.; Harbich, W.; Monot, R.; Buttet, J.; Kern, K. Science 1996, 274, 956.

(35) Bikondoa, O.; Pang, C. L.; Ithnin, R.; Muryn, C. A.; Onishi, H.; Thornton, G. Nat. Mater. 2006, 5, 189.

(36) Isomura, N.; Wu, X.; Watanabe, Y. J. Chem. Phys. 2009, 131, 164707.

(37) Lundwall, M. J.; McClure, S. M.; Goodman, D. W. J. Phys. Chem. C 2010, 114, 7904.

(38) Rashkeev, S. N.; Lupini, A. R.; Overbury, S. H.; Pennycook, S. J.; Pantelides, S. T. Phys. Rev. B 2007, 76, 035438.

(39) Bowker, M.; Bennett, R. A. J. Phys.: Condens. Matter 2009, 21, 474224.

(40) Ouyang, R. H.; Liu, J. X.; Li, W. X. J. Am. Chem. Soc. 2013, 135, 1760.

(41) Campbell, C. T.; Ertl, G.; Kuipers, H.; Segner, J. J. Chem. Phys. 1980, 73, 5862.

(42) Ji, X. Z.; Somorjai, G. A. J. Phys. Chem. B 2005, 109, 22530.

(43) Ji, X. Z.; Zuppero, A.; Gidwani, J. M.; Somorjai, G. A. Nano Lett. 2005, 5, 753. 